\title{
Pat Thane and Tanya Evans: Sinners? Scroungers? Saints? Unmarried Motherhood in Twentieth-Century England
}

\author{
Karin Wall
}

Published online: 10 October 2014

(C) Springer Science+Business Media Dordrecht 2014

This book offers a rich and comprehensive historical analysis of how policies, public debate, voluntary action and social context shaped the lives of unmarried mothers and attitudes towards them in twentieth-century England. The study combines the history of a particular group, in this case unmarried lone parents, with the history of the National Council of the Unmarried Mother and Her Child (NC), a voluntary organization established in 1918. It draws mainly on the NC's archives: annual reports, research commissioned by the organization and examples of the often dramatic cases of mothers requesting advice and help; but it also relies on demographic statistics, developments in family policy, parliamentary debates, social research on lone parents, debates in the media, biographies and interviews. More than just an account of unmarried motherhood, the research shows how changes in law, gender relations, welfare provision, political and popular discourses, war and peace, are the bed-rock of the social construction and meanings of parenthood over time. Spanning analysis across a whole century is a major challenge. In doing so, the book reveals the breath-taking complexity of understanding change and continuity in society's treatment of family living arrangements and diverse forms of motherhood and fatherhood.

The book adopts a chronological approach, beginning in early 20th England and moving, chapter by chapter, over the course of the twentieth century and up to first decade of the twenty first century. The core analytical structure of each chapter is the same: the changing numbers of single mothers and other demographic data (e.g., infant mortality rates, marriage and cohabitation), unmarried motherhood and sexuality as public issues, the work of the NC and other political or social actors, the

K. Wall (ه)

Institute of Social Sciences, University of Lisbon, Lisbon, Portugal

e-mail: karin.wall@ics.ul.pt 
experiences of unmarried mothers before and after giving birth and in different social classes.

Among the many insights provided by this research, the following may be highlighted. First, the high numbers and the extreme vulnerability and stigmatization of unmarried mothers in early twentieth-century England. Shame, social exclusion, the need to silence and render invisible, high rates of infant mortality, mothers taken into strict and punitive institutions, forced separation from the baby, giving up for adoption, despair leading to suicide, poor job opportunities, these are some of the reasons which triggered the expansion of voluntary action to support mothers.

Secondly, countering this conventional narrative of victimization, the authors emphasize the diversity of experiences and pathways. Even in the first half of the previous century, unmarried mothers came from every kind of social background, some were isolated and impoverished, some were cohabiting with the father, others lived with supportive parents, usually secretively, with the child growing up believing that their mother was a sister, a few were well-known figures provided for by absent fathers.

A third point is the crucial role played by the Second World War and the welfare state. The authors dispel the idea that the war was a time of sexual immorality but they do show that the war was a turning point in terms of social attitudes and welfare provision. The 'veil of secrecy' surrounding illegitimacy was lifted, gender cultural models began to shift, statistics became available for evidence-based policy-making, and the lessons from wartime experiences contributed to the postwar reform of policy and service provision.

Over the last few decades, and contrary to the expectations of the $\mathrm{NC}$, analysis shows that the problems of single mothers, and of lone parents in general, continue to be a concern for both the state and voluntary organizations. Access to benefits, new legislation (differences between legitimate and illegitimate children were only abolished in 1987), growing female employment and acceptance of family diversity did not eradicate discrimination, poverty and recurrent moral panics concerning lone parents. By contrast, it made for new challenges: establishing cooperation between state and non-governmental organizations, providing training and education, enhancing awareness of entitlements, lobbying for daycare, countering new stereotypes of lone mothers, in particular in the context of 'back to basics' politics and retrenchment of the welfare state.

Overall then this is an invaluable book for anyone interested in understanding the history of unmarried motherhood and voluntary action in a specific welfare regime and in grasping the social and political processes responsible for change in family life over time. From a critical perspective, some additional information on the lived experiences of mothers as from the 80 s onwards, drawing on qualitative studies or other material, would have given the problems and the diversity of contemporary single mothers more visibility; the focus of the last three chapters on politics and policies rather loses touch with mothers' voices. Some initial reflection on the methods and sources used would also have been welcome. More broadly, it would be important to have examined, or at least located, the specificity of unmarried motherhood and voluntary action in England against the backdrop of developments in other European welfare regimes. 